\title{
A LEGISLAÇÃO BRASILEIRA E A RECUPERAÇÃO DE MENORES INFRATORES
}

\section{THE BRAZILIAN LEGISLATION AND THE RECOVERING OF JUVENILE OFFENDERS}

\author{
${ }^{1}$ Álvaro Gonçalves Antunes Andreucci \\ ${ }^{2}$ Joao Gustavo Dantas Chiaradia Jacob
}

\section{RESUMO}

O presente artigo trata do panorama histórico da legislação brasileira a respeito da punição e recuperação de menores infratores. Começa com a definição psicológica do que seja a infância e adolescência em relação ao desenvolvimento humano, e analisa os diplomas legais existentes concernentes à infração praticada por menores de idade no decorrer da história legislativa brasileira. Mostra que há, de um lado, uma preocupação fundamentada com a assistência ao menor, e a proteção que a ele é dada em situação de vulnerabilidade. Apresenta ainda quais as lacunas existentes que impossibilitam a efetiva recuperação de menores em conflito com a lei, criticando, ao final, a política simplista da adoção da redução da maioridade penal, como forma de reduzir a criminalidade praticada por menores de dezoito anos.

Palavras-chave: Maioridade penal, Delinquência juvenil, História do direito

\begin{abstract}
This article treats of the historical background of Brazilian legislation concerning the punishment and rehabilitation of juvenile offenders. It begins with the psychological definition of what childhood and adolescence in relation to human development, and analyzes the existing legislation concerning the violation perpetrated by minors during the Brazilian legislative history. It shows that there is, on the one hand, a concern founded with the assistance to the lower, and the protection that is given to him in a vulnerable situation. It also presents which the gaps that prevent the effective recovery of minors in conflict with the law, criticizing, in the end, the simplistic policy of adopting the reduction of criminal responsibility as a way of reducing crime committed by persons below eighteen years.
\end{abstract}

Keywords: Criminal majority, Juvenile delinquency, History of law

\footnotetext{
${ }^{1}$ Doutor em História Social pela Universidade de São Paulo - USP, São Paulo - SP (Brasil) Professor da Universidade Nove de Julho - UNINOVE, São Paulo - SP (Brasil).

E-mail: bareska@gmail.com

${ }^{2}$ Mestrado em andamento em Direito na Universidade Nove de Julho - UNINOVE, São Paulo - SP (Brasil). Professor da Universidade Nove de Julho - UNINOVE, São Paulo - SP (Brasil).

E-mail: joaogjacob@ hotmail.com
} 


\section{INTRODUÇÃO}

O tema da redução da maioridade penal tem ocupado manchetes de jornal e sido objeto de constantes e acaloradas discussões. Colocada na pauta de votações do Poder Legislativo brasileiro, há uma provável sinalização de que a maioridade penal deverá ser reduzida, em que pese a existência de protestos (tímidos, é verdade), mas que servem de contraponto para uma pretensão que não parece ser a mais lógica e adequada, tanto do ponto de vista científico, como do ponto de vista legal.

Desde que o Brasil adotou, pela primeira vez, uma legislação específica para cuidar de menores em conflito com a lei, o fez de maneira muito insípida, cuidando apenas de adaptar ao cenário em que se inclui o menor, a legislação punitiva aplicada aos adultos.

Como se verá no presente artigo, muito pouco se cuidou da questão do ponto de vista técnico ou científico; o problema se resumiu à esfera penal, e assim mesmo, de maneira muito aquém do que deveria ser realmente tratada, deixando de lado aspectos importantes no tocante à recuperação e ressocialização do adolescente em conflito com a lei.

Tendo em vista este percurso histórico, podemos afirmar que o Brasil não se preocupou devidamente com seus menores e, muito menos, com aqueles que cometeram e cometem crimes, pequenos ou não. Se os estabelecimentos destinados à recuperação de menores infratores são considerados universidades do crime, os responsáveis pelo currículo são, sem dú vida, o Estado e a sociedade brasileiros.

Para se pensar sobre educação e cidadania no Brasil e instituir um debater maduro sobre nosso modelo punitivo, não é possível deixar passar esta oportunidade de compreendermos o alcance e significado da proposta em curso sobre a Maioridade Penal. Nesse sentido, é necessário recuperarmos um pouco de nossa história sobre a punição de crianças e adolescentes, bem como de nossa realidade atual sobre o jovem delinquente para avaliarmos o que está em jogo. Além de expormos o debate em torno desta proposta legislativa, o presente artigo vai apresentar soluções possíveis de serem aplicadas, de forma alternativa, sem que seja necessário se recorrer à redução da maioridade penal, que, como se depreende facilmente, é mais uma questão política do que de ciência psicológica ou de ciência do Direito. 


\section{O PRIMEIRO CÓDIGO DE MENORES (1926)}

Até o ano de 1926, não havia uma legislação consolidada específica que tratasse da delinquência juvenil.

Segundo as Ordenações Filipinas, vigentes quando D. João VI chegou ao Brasil em 1808, a imputabilidade penal se iniciava aos sete anos de idade. Entre dezessete e vinte e um anos de idade, o adolescente era considerado um "jovem adulto", e já era submetido a penas mais severas. Após os vinte e um anos, a imputabilidade penal era absoluta, e o jovem podia ser inclusive condenado à pena de morte.

Em 1830, com o advento do Código Penal do Império - o primeiro Código Penal do Brasil - a imputabilidade penal plena foi fixada em quatorze anos. Os menores entre sete e quatorze anos eram submetidos a um sistema de correção baseado em critérios biopsicológicos, ou seja, se tivessem discernimento do ato praticado eram internados nas chamadas "casas de correção", pelo tempo em que o juiz entendesse necessário, desde que o menor não ficasse internado após os dezessete anos de idade.

Em 1890 foi promulgado o primeiro Código Penal da República, o Código Penal dos Estados Unidos do Brasil. Segundo esse Código, a imputabilidade penal plena permaneceu fixada em quatorze anos de idade; entretanto, a imputação relativa foi fixada em nove anos de idade.

A partir do início do século XX, começou a surgir no mundo uma preocupação com as condições da criança e do adolescente, culminando na constatação de que a criança e o adolescente são pessoas dotadas de personalidade distinta da dos adultos.

E no Brasil não foi diferente; novas formas de pensamentos e conceitos trazidos pelos ideais republicanos levaram intelectuais e políticos brasileiros a adotarem os mesmos conceitos relativos à criança e ao adolescente que já vigiam no resto do mundo.

E foi nesse cenário, e influenciado pelo novo modelo republicano vigente que foi promulgado, em 1926, o Código de Menores ${ }^{1}$.

Pela primeira vez, ainda que timidamente, a legislação brasileira passou a se preocupar com a assistência social ao menor, mormente o abandonado. Foi por intermédio desse Decreto abolido o denominado "sistema das rodas.",

\footnotetext{
1 Decreto 5083, de $1 .^{\circ}$ de dezembro de 1926.

2 Sistema das Rodas, ou Roda dos Injeitados: Era um compartimento de forma circular que havia em orfanatos, com uma das aberturas voltada para a rua, e que servia para que fossem ali colocadas crianças recém-nascidas, principalmente filhas de mães solteiras, de forma anônima.
} 
Pela primeira vez também ficou estabelecido que o menor de quatorze anos não estaria submetido a qualquer processo penal. Ficou também estabelecido que o menor com idade compreendida entre quatorze e dezoito anos que praticasse crime, ficaria sujeito a internação em uma instituição de reeducação ("escola de reforma"). Entretanto, não havia previsão de um processo ou procedimento específico para esse fim.

O Código instituiu ainda a "Liberdade Vigiada", regulando detalhadamente as causas que a autorizavam, bem como o procedimento para sua adoção.

Em seguida, pouco menos de um ano depois, foi promulgado um novo Código de Menores, com disposições mais específicas, principalmente no tocante a prática de infrações penais por menores de idade.

\section{O CÓDIGO DE MENORES DE 1927}

O Código de Menores de $1927^{3}$ é considerado por muitos como sendo o primeiro código de menores, a primeira consolidação de leis a respeito de menores de idade, abandonados ou delinquentes, da legislação brasileira. Porém, vimos que é um engano, pois já em 1926 fora promulgado o primeiro código.

Percebe-se claramente que o código de 1926 serviu de inspiração para a elaboração do Código de 1927, uma vez que há no texto reproduções integrais de dispositivos já constantes do código anterior.

Realizando um estudo comparativo, conclui-se que o Código de 1926 trouxe linhas gerais, principalmente no tocante à prática de infrações por menores de idade. Com relação a assistência, o Código foi mais abrangente, detalhando procedimentos a serem observados em caso de menores abandonados ou em situação irregular.

Nota-se que a atenção dada a menores infratores era mínima, restringindo-se tão somente à separação desses menores dos criminosos adultos. Não há qualquer previsão mais detalhada visando à assistência e recuperação do menor infrator.

Processualmente falando, não havia anteriormente um processo ou procedimento especial, o que só veio a ocorrer com a promulgação do Código de Menores de 1927. Em seu artigo 68, o Código estabeleceu um procedimento para julgamento de menores infratores.

\footnotetext{
3 Decreto n. ${ }^{\circ} 17943-$ A, de 12 de outubro de 1927.
} 
É curioso notar que o Código estabelecia uma condição especial, na qual o menor com idade compreendida entre dezesseis e dezoito anos de idade, a quem fosse imputada a autoria de crime grave, e que fosse considerado perigoso, deveria ser recolhido a um estabelecimento penal destinado a condenados de menor idade, ou em estabelecimento penal destinado a adultos, mas separado dos demais. 4

O Código de Menores de 1927 Previu ainda como circunstância atenuante da pena o fato de uma pessoa com idade compreendida entre dezoito e vinte e um anos vir a cometer um crime.

Numa abordagem comparativa, temos que o Código de Menores de 1926 trouxe disposições gerais sobre menores. Entretanto, com relação a menores abandonados, tais disposições foram menos genéricas. Com relação à prática de infrações penais, o Código se limitou a definir a idade mínima para a imputabilidade penal, prescrevendo, ainda, a necessidade da existência de um estabelecimento onde o menor infrator ficasse internado, o que possibilitaria, em tese, sua recuperação.

Já o Código de 1927 preocupou-se mais em estabelecer normas mais específicas de caráter penal e processual penal em relação a menores infratores; também trouxe normas mais específicas em relação aos procedimentos a serem adotados no tocante aos menores abandonados.

O que se percebe nos dois primeiros códigos, e o que se perceberá no decorrer da análise de outros diplomas legais pertinentes ao tema, é que a legislação brasileira se preocupou (e ainda se preocupa) em normatizar com riqueza de detalhes a situação do menor abandonado; entretanto, ao cuidar da questão do menor infrator, as disposições guardam feições de generalidade, sendo pouco detalhadas, como se o problema do menor infrator não merecesse a mesma atenção do Poder Público do que outras questões.

\section{A LEI 5258/67 E A LEI 5439/68}

A Lei n. ${ }^{\circ}$ 5258, de 10 de abril de 1967, foi uma lei promulgada durante a Ditadura Militar visando estabelecer regras gerais de procedimento em caso de cometimento de infrações penais por menores de idade.

\footnotetext{
${ }^{4}$ Decreto n. ${ }^{\circ} 17943-A$, de 12 de outubro de 1927, artigo 71.
} 
Permaneceram as regras vigentes do Código de 1927; o que a Lei 5258/67 trouxe, foram apenas adaptações, visando preencher possíveis lacunas existentes.

A Lei n. ${ }^{\circ} 5439$, de 22 de maio de 1968 foi promulgada apenas com o fito de reformar a Lei anterior, a de . $^{\circ}$ 5258/67.

Assim, não há qualquer inovação maior com a promulgação dessas duas leis no que diz respeito a uma ampliação da preocupação de se amparar e oportunizar uma reeducação do jovem.

\section{O CÓDIGO DE MENORES DE 1979}

O ano de 1979 foi considerado pela ONU o Ano Internacional da Criança.

Nada mais oportuno, portanto, que o Poder Legislativo brasileiro se ocupasse da reforma da legislação concernente aos menores de idade. Além disso, o país vivia o início da abertura democrática, e algumas reformas já eram mais do que necessárias.

Como vimos, ainda vigorava o Código de Menores de 1927, com as poucas alterações trazidas pelas leis 5258/67, e 5439/68.

Assim, foi promulgada em 10 de outubro de 1979, a Lei n. ${ }^{\circ} 6697$, que Instituiu o Código de Menores. Esta revogou todas as legislações anteriores, inclusive no tocante à adoção; no entanto, manteve a mesma estrutura das leis anteriores.

Novamente houve uma preocupação com a situação do menor abandonado, preocupação essa que não ganhou o mesmo quilate em relação ao menor infrator.

Nesse particular, apenas disciplinou o procedimento de instrução e julgamento de infrações penais por menor de idade. Manteve a imputabilidade penal plena os dezoito anos de idade.

\section{O ESTATUTO DA CRIANÇA E DO ADOLESCENTE (ECA)}

Em 1988, foi promulgada a nova Constituição da República Federativa do Brasil, causando um rompimento com toda a ordem jurídica e política vigentes até então. 
Finalmente o Brasil foi alçado à condição de país democrático. Mais: tornou-se um Estado Democrático de Direito, alinhado à mais moderna doutrina de proteção aos Direitos Humanos.

Assim, era mais do que esperado que pelo menos boa parte da legislação brasileira fosse reformada, tendo em vista a nova ordem que passava a vigorar no país. E foi dessa forma, seguindo a nova tendência, que foi promulgada, em 13 de julho de 1990, a Lei 8069, que foi denominada Estatuto da Criança e do Adolescente (ECA).

Considerada a legislação mais completa a respeito do assunto, o ECA, como ficou conhecido, inseriu a criança e o adolescente no cenário jurídico e legal brasileiro, tornando-os efetivamente sujeitos de direito, pessoas com direito à dignidade. A criança e o adolescente se tornaram, pois, pessoas.

Ao longo de 267 artigos, o ECA disciplinou de forma detalhada todas as questões que haviam sido tratadas de maneira genérica nas leis anteriores.

Distinguiu, por exemplo, criança de adolescente; tratou da questão da adoção; colocou a criança e o adolescente sob a tutela dos interesses difusos e coletivos.

No âmbito do Direito Penal, disciplinou em detalhes o procedimento relativo à prática de infrações penais por menor de idade. Também definiu a natureza e os casos de imposição de medidas punitivas a serem adotadas em desfavor de menor de idade.

Pela primeira vez, definiu que o menor pratica ato infracional, e não crime, dando, assim, natureza e essência diversas da prática de infração quando perpetrada por adolescente ${ }^{5}$. Sim, por adolescente, pois, segundo a prescrição do então novel estatuto, a criança, cuja idade vai de zero a doze anos, não pode ser responsabilizada de maneira alguma pela prática de ato infracional, ao passo que o adolescente, cuja idade prevista é a compreendida no período que vai de treze a dezessete anos, é responsabilizado, porém, de maneira diferenciada, adequada, segundo a legislação ao seu desenvolvimento físico e mental.

Depreende-se, pois, que, pela primeira vez na história da legislação brasileira o menor passou a ter um estatuto a lhe proteger, em todos os aspectos.

O ECA sofreu diversas alterações ao longo do tempo, mas nenhuma que efetivamente viesse a trazer prejuízo à criança ou ao adolescente. Todas elas visaram a inserir mais ainda o menor no contexto social, bem como torna-lo cada vez mais sujeito de direitos, fazendo-o pessoa distinta e distinguida, em todos os aspectos.

\footnotetext{
${ }^{5}$ Lei 8069/90, artigo 103: "Considera-se ato infracional a conduta descrita como crime ou contravenção penal."
} 


\section{INFÂNCIA E ADOLESCÊNCIA: CONCEITOS PSICOLÓGICOS}

No estudo do desenvolvimento humano, e, em se tratando especificamente de desenvolvimento psicológico e social, há que se considerar o que seja infância e adolescência do ponto de vista psicológico.

Atualmente, do ponto de vista da medicina, já se tem estudos e conceitos estabelecidos, que servem de paradigma para estudos outros visando o entendimento do que seja infância e adolescência do ponto de vista físico, de desenvolvimento do corpo humano.

Entretanto, se tal entendimento do ponto de vista físico interessa para o Direito, o entendimento do que seja infância e adolescência do ponto de vista psicológico interessa muito mais, pois é por meio de sua sofisticação cognitiva que o jovem vai desenvolver suas relações pessoais e sociais, inteirando-se com o mundo à sua volta.

Também é o conceito psicológico do que seja infância e adolescência que vai interessar diretamente ao Direito, notadamente ao Direito Penal, uma vez que é a maturidade do jovem infrator que vai definir seu entendimento do que seja o ato infracional que porventura venha a praticar. Não se pode desprezar ainda a influência que o ambiente social e familiar em que o jovem esteja inserido exerce sobre a formação de sua personalidade. Além disso, o ambiente social e familiar (ou a falta deles) irá ser preponderante quando o jovem se vir envolvido na prática de atos infracionais.

\subsection{O Conceito Psicológico de Infância}

Para podermos compreender melhor o tema da delinquência infanto-juvenil é importante compreendermos e adotarmos, cientificamente, a definição destes termos. A Psicologia divide o desenvolvimento infantil em três fases ${ }^{6}$ :

- Desenvolvimento físico, cognitivo e psicossocial nos três primeiros anos: Fisicamente, o período inicial de três anos é caracterizado pela adaptação ao meio externo, à vida fora do útero; o aspecto cognitivo é marcado pelo desenvolvimento do cérebro, e consequentemente pelo desenvolvimento da memória; a criança inicia a aprendizagem. É necessário ressaltar que seis abordagens teóricas diferentes explicaram os processos de aprendizagem infantil. ${ }^{7}$

\footnotetext{
6 FELDMAN, Ruth Duskin; PAPALIA, Diane E. Desenvolvimento Humano. Tradução de Cristina Monteiro e Mauro de Campos Silva. Porto Alegre: AMGH Editora, 2013.

7 Behaviorista, Psicométrica, Piagetiana, Do Processamento da Informação, Da Neurociência Cognitiva, Sociocontextual.
} 


\section{- Desenvolvimento físico, cognitivo e psicossocial na segunda infância: A} segunda infância compreende o período entre três e seis anos de idade; fisicamente, crescem e emagrecem; ficam mais fortes; o sistema nervoso, incluindo o cérebro, ainda está em desenvolvimento; os sistemas imunológico e esquelético se fortalecem. O desenvolvimento de áreas sensoriais e motoras do córtex cerebral permite a coordenação entre o que a criança quer fazer, e o que ela pode fazer. Há o desenvolvimento das habilidades motoras grossas (correr, saltar, etc...), que se intensifica com as atividades escolares.

No aspecto cognitivo, desenvolvem, entre outras habilidades, a compreensão dos números, a consciência da atividade mental, e o entendimento de causa e efeito.

Psicossocialmente, nessa fase a criança começa a desenvolver o autoconceito, que inclui a autodefinição ${ }^{8}$ e a autoestima. Como parte do desenvolvimento do autoconceito, é o desenvolvimento da identidade de gênero, ou seja, a consciência de ser do sexo masculino ou feminino. É a fase em que a criança começa a entender e a regular as emoções, embora ainda tenha dificuldades de lidar com emoções conflitantes.

É necessário ressaltar que brincar é a principal atividade da segunda infância. Papalia, citando Parry ${ }^{9}$ traz uma consideração importante para o presente artigo: "Preocupado com o menino da rua cujas brincadeiras são sempre muito agressivas? Com toda probabilidade, não há nada com que se preocupar. A pesquisa sugere que não há ligação entre brincadeira agressiva e posterior criminalidade."

- Desenvolvimento físico, cognitivo e psicossocial na terceira infância: A terceira infância compreende o período que vai dos seis aos onze anos de idade. No aspecto físico, esse período se caracteriza por um crescimento lento. As diferenças parecem (e o são) maiores, uma vez que esse período compreende um lapso temporal extenso.

As necessidades de sono diminuem, e células cerebrais que não são mais utilizadas perdem densidade, ou são substituídas por outras. As habilidades motoras permitem a prática de esportes pouco mais intensos, o que desenvolve a agilidade.

\footnotetext{
${ }^{8}$ Autodefinição: Conjunto de características usadas para descrever a própria pessoa. (PAPALIA, 2013.)

${ }^{9}$ PARRY, W.(2010, August, 29). Bring it; Boys make benefit from agressive play. Today Health. Retrieved from http://today.msnbc.msn.com/id/38882665/ns/health-kids_and_parenting/
} 
Do ponto de vista cognitivo, as crianças na terceira infância desenvolvem o que Piaget chama de estágio operatório-concreto, em que fazem uso de operações mentais para resolver problemas concretos, desenvolvendo certo raciocínio lógico, porém limitado ao aqui e agora. Conseguem ir e voltar da escola, bem como elaborar e interpretar mapas rudimentares, além de calcular distâncias.

Socialmente, a terceira infância é o período em que a criança vai atrelar sua autoestima à produtividade; amizades tendem a se desenvolver nesse período, mas desde que haja coincidência de interesses, idade e sexo.

É nesse período que garotos agressivos tendem a ganhar status social, uma vez que esse tipo de comportamento concede glamour perante os outros colegas.

A ocorrência de divórcio entre os pais não costuma afetar as crianças nessa idade, desde que o genitor que não tem a guarda seja presente.

O fato de a criança ser filha de um casal homoafetivo também não influencia na vida cognitiva ou psicossocial da criança nessa fase.

Como visto no presente capítulo, baseados nos estudos de Feldman e Papalia (2013), a infância possui três fases de desenvolvimento, bem definidas, merecendo destaque para o desenvolvimento físico e cognitivo, bem acentuados nestes períodos, o que acarreta necessidades específicas para um propício desenvolvimento psico-motor. O convívio familiar exerce certa influência, bem como já se vislumbra uma vida social incipiente. Entretanto, tais influências se darão de forma mais acentuada no período da adolescência, que será objeto de estudo no próximo capítulo.

\subsection{O Conceito Psicológico de Adolescência}

É o período mais sensível do desenvolvimento humano, mormente nos âmbitos físico e psicossocial.

A adolescência é, portanto, um período intermediário, onde o jovem ainda não deixou totalmente o período da infância, e nem entrou verdadeiramente na fase adulta, o que acarreta muitos questionamentos, e insatisfações também.

Fisicamente, é a fase das transformações, quando os hormônios, notadamente os de natureza sexual, provocam transformações definitivas no corpo do jovem. É necessário ressaltar que os mesmos hormônios que provocam as transformações físicas, também irão 
provocar importantes transformações no comportamento do adolescente. O amadurecimento sexual chega ao seu ápice.

No aspecto cognitivo, é na adolescência que o ser humano conhece um aumento da sua capacidade de raciocinar e pensar, mas, muitas vezes seu pensamento ainda é imaturo em alguns aspectos. Nessa fase, o adolescente consegue trabalhar melhor seu raciocínio abstrato, e é capaz de desenvolver julgamentos morais mais sofisticados.

É na adolescência que o jovem geralmente pode passar a ter contato com o álcool e com outras drogas, lícitas, ou ilícitas; esse contato é resultado do processo de socialização, somado à necessidade de se autoafirmar-se; além disso, o fato de estar em um nível intermediário de desenvolvimento, faz com que o adolescente se torne questionador, muito como resultado dos anseios e medos que enfrenta em razão da entrada na vida adulta, bem como das dúvidas surgidas por conta da falta de autoconhecimento pleno.

É também na adolescência onde, geralmente, o ser humano pode vir a desenvolver comportamento antissocial, e, assim, vir a praticar os primeiros atos infracionais, podendo tornar-se um delinquente juvenil.

\subsection{Possíveis Causas do Comportamento Antissocial e da Delinquência Juvenil}

Quais causas podem determinar o desenvolvimento de um comportamento antissocial, bem como a delinquência juvenil?

Em que pese a existência sempre de situações imponderáveis dada a imprevisibilidade de inúmeros fatores que podem definir o livre arbítrio, atualmente há fatores de risco de natureza biológica e genética, tais como a existência de déficits neurobiológicos em porções do cérebro que regulam as reações ao estresse; Rhee e Waldman ${ }^{10}$ afirmam que o comportamento antissocial tende a ocorrer em diversos casos em uma mesma família, e que estudos concluíram que os genes influenciam de $40 \%$ a $50 \%$ da variação no comportamento antissocial dentro de uma população, e de $60 \%$ a $65 \%$ da variação no comportamento antissocial agressivo.

Entretanto, não são somente os fatores biológicos e genéticos que se tornam determinantes no desenvolvimento do comportamento antissocial e agressivo, bem como da delinquência juvenil.

10 RHEE, S.H.; WALDMAN, I.D. Genetic and environmental influences on antisocial behavior: A meta-analysis of twin and adoption studies. Psychological Bulletin, 128, 490-529. In: FELDMAN, Ruth Duskin; PAPALIA, Diane E. Desenvolvimento Humano. Tradução de Cristina Monteiro e Mauro de Campos Silva. Porto Alegre: AMGH Editora, 2013. 
Pesquisas mostraram a ocorrência de dois tipos de causas para o comportamento antissocial:

-Comportamento Antissocial de Início Precoce: Detectado por volta dos onze anos de idade; é decorrente de parentalidade ineficaz, podendo ainda ser resultado de maustratos e outras formas de violência vividas e/ou presenciadas no ambiente doméstico. Tende a resultar em delinquência juvenil crônica na adolescência.

- Comportamento Antissocial de Início Tardio: Detectado logo após o início da puberdade, está relacionado com as mudanças típicas da adolescência, e com o descompasso entre a maturidade biológica e social; também é incrementado pela parentalidade ineficaz. Aqui, o convívio com amigos e outros pares de conduta semelhante tende a reforçar o comportamento antissocial e a ocorrência de delinquência juvenil que, nesse caso, tende a desaparecer tão logo cessem os fatores determinantes do comportamento antissocial, sejam eles sociais ou biológicos.

Tanto o comportamento antissocial de início precoce quanto o de início tardio encontram na família (ou na ausência dela), os fatores desencadeantes ou determinantes de tais comportamentos, que poderão redundar em delinquência juvenil, podendo ainda redundar em delinquência já na fase adulta.

É de se ressaltar que muitos adolescentes que apresentam comportamento antissocial de início tardio desenvolvem esse comportamento, adotando, concomitantemente, ou alternadamente, comportamento de acordo com as regras, para receberem atenção dos pais e do meio em que vivem, e verem reforçadas suas atitudes positivas, tudo como forma de despertar uma atenção inexistente ou ineficiente por parte da família.

Como se pôde observar no presente capítulo, ainda que de forma sucinta, a formação de uma personalidade é um processo complexo e que envolve fatores físicos, sociais e psicológicos. A ocorrência de comportamento antissocial na adolescência e a possível superveniência de delinquência juvenil, que pode se estender para a fase adulta, também é resultante de um processo que pode se iniciar ainda na primeira fase da infância. É importante ressaltar que os estudos psicológicos, ainda que tratem de possibilidades e de estatísticas, revelam que o indivíduo, nestas fases iniciais que antecedem a vida adulta, está ainda experimentando o mundo e construindo valores e significados sobre as respostam que obtêm de seu entorno. Nesse sentido, não só ele ainda não possui um pensamento autônomo como, 
também, apresenta-se bastante maleável e apto a formar novas formas de entendimento sobre as narrativas do mundo.

Como observamos, não houve, e não há, por parte dos legisladores brasileiros ao longo do tempo, uma preocupação em observar esse processo complexo na elaboração de leis que visem a possibilidade de transformar (reabilitar) o adolescente, dando-lhe novas oportunidades que não somente aquela do caminho da delinquência.

\section{COMO A LEGISLAÇÃO E O ESTADO BRASILEIRO TRATAM A QUESTÃO DO MENOR INFRATOR}

A legislação brasileira preocupou-se tardiamente com a questão do menor infrator; isso é facilmente constatado ao se analisar os diversos diplomas legais promulgados no decorrer da História do Brasil.

Se, por um lado, a legislação avançou e se preocupou com a questão do menor abandonado e da adoção, por outro lado, as normas relativas à prevenção e recuperação de menores infratores foram e são de caráter genérico, sem disciplinar a fundo uma questão sumamente delicada.

Mesmo o inovador Estatuto da Criança e do Adolescente, que colocou a criança brasileira como sujeito de Direitos Humanos, ao disciplinar a questão do menor infrator, pouco inovou, seguindo, com algumas poucas modificações, o que já era previsto nas leis anteriores.

O que se conclui como resultado dessa análise, é que o Estado Brasileiro se ocupou da definição de uma idade mínima para o início da imputabilidade penal plena. No mais, preocupou-se em estabelecer uma política segregacionista para o menor infrator, sob a justificativa de não misturá-lo com criminosos maiores de idade.

Não foi o que se viu, e nem é o que se vê. Os estabelecimentos destinados à recuperação de menores infratores são apenas cadeias para jovens. Foram construídos com essa finalidade, de provocar impacto psicológico, além de ressaltar o caráter apenas retributivo da punição. Tome-se como exemplo a recente denúncia de maus tratos cometidos contra menores internos da Unidade Cedro da Fundação Casa- Complexo Raposo Tavares. ${ }^{11}$

\footnotetext{
11 http://g.globo.com/sao-paulo/noticia/2015/07/jovens-sao-agredidos-na-fundacao-casa-diz-defensoria-mp-abre- $\underline{\text { acao.html. }}$ Acesso em 17/08/2015.
} 
Em que pese haverem diretrizes e algumas políticas públicas no sentido da recuperação, não há um projeto pedagógico consistente que possibilite pelo menos a tentativa de recuperação daquele menor infrator, muito por causa da maneira em que tais estabelecimentos foram construídos e as políticas estabelecidas. O que se viu foi um enfraquecimento do já deficiente projeto de recuperação.

Tem-se, pois, um caminho que conduz a destinos opostos: uma legislação que tenta, ainda que de forma incipiente, disciplinar a questão do menor infrator, em conflito com a política segregacionista por ela mesmo imposta, aliada à falta de projetos pedagógicos efetivos, e da adoção do conceito, ainda que não oficial, de que os estabelecimentos destinados à internação de jovens infratores são apenas prisões para menores de idade.

Aliás, o mesmo acontece com os criminosos maiores de idade; a falta de diretrizes consistentes e de projetos pedagógicos eficazes redunda não só na reincidência, mas também no caos que vimos surgir de há muito no sistema prisional brasileiro.

Como resultado lógico temos que há apenas dois tipos iguais de prisões no Brasil: uma para maiores, e outra para menores.

\section{CONSIDERAÇÕES FINAIS}

Diante de todo o exposto, depreende-se que a tão preconizada redução da maioridade penal não pode ser considerada o caminho da solução para a redução da criminalidade no Brasil. Tanto a análise histórica como a abordagem psicológica nos mostram que a questão é muito mais complexa do que uma solução meramente punitiva. A responsabilidade pelo tema deve ser compreendida de forma ampla, como sendo de toda a sociedade brasileira e, ainda, como um fenômeno que deve ser repensado a partir de uma dinâmica da prevenção e da construção de opções de formação do jovem para o convívio em sociedade.

É uma solução simplista, despida de qualquer análise técnica mais séria e cuidadosa, pensar que a simples diminuição da maioridade penal resolveria o problema, pois o número de infrações praticadas por jovens não seria diminuído ou mesmo inibido, uma vez que questões importantes, tais como a recuperação do jovem infrator e a prevenção não estão sendo 
considerados nos debates a respeito. O que vai acontecer de prático é que as prisões para menores ficarão um pouco mais vazias do que as prisões comuns.

Como vimos, a legislação brasileira no tocante a menores infratores é a mesma de 1926, apenas reformada em alguns aspectos sem maior profundidade. O ECA, apesar de grande avanço no que tange à inserção do menor como sujeito de direitos fundamentais, deixa ainda a desejar quanto a normas programáticas e políticas públicas efetivas que recuperem o menor infrator e mantenham os menores afastados da influência do crime.

Soluções, desde que pensadas de maneira serena e que sejam definidas como sendo passíveis de adoção a curto, médio e longo prazo, podem envolver toda a sociedade de forma a construir um futuro que valorize a cidadania e a credibilidade na educação dos jovens.

Podemos apontar, em âmbito legislativo, uma ruptura total com a legislação vigente; é preciso que se abandone o Código de 1926, e se promova uma ampla reforma. Para tanto, não há como se desprezar o que diz a Academia. É preciso que se constitua uma comissão de notáveis não só do Direito, mas interdisciplinar, incluindo ai cientistas da Educação, Psicologia, Sociologia, história, etc.

Nessa nova legislação, é necessário que se dê o devido espaço ao procedimento a ser adotado com relação à prática de infração penal por menor de idade. Em que pese o ECA ter inovado substancialmente em todas as matérias, inclusive em matéria penal e processual penal, percebe-se que ainda há muito a desejar.

Quem estuda o ECA, pode constatar que o Brasil possui uma política eficaz de proteção e recuperação de menores de idade e que, facilmente deve estar realizando a recuperação de seus jovens infratores. Porém, não é bem assim. A legislação é de alta qualidade mas, os encarregados do cumprimento da Lei, bem como aqueles cuja responsabilidade é propiciar mecanismos de recuperação para que o jovem infrator não permaneça na criminalidade não conseguem pô-la em prática. Uma tradição paternalista aliada ao descaso para com a criança dificultam a compreensão de sua individualidade e especificidade quanto ao tratamento penal. Podemos observar isso na maneira utilizada nos estabelecimentos destinados a recuperar menores infratores com a finalidade de controla-los, pois esta é a mesma usada em presídios de adultos, ou seja, a partir do uso da força física, muitas vezes desproporcional.

A adolescência é um período em que fisicamente o ser humano possui suas idiossincrasias, muitas de cunho hormonal. O menor, então, é agitado, tem um 
comportamento diferenciado, mas muito por conta de sua constituição física e fisiológica, não por maldade ou deficiência de caráter.

Não se pode, pois, legislar e regular com base na exceção; porque há exceções; há pessoas que nascem psicopatas, esquizofrênicas, e mesmo más por índole, mas isso claramente é uma exceção.

Ser humano nenhum pode ser tratado de maneira genérica; é preciso que haja uma coincidência de atitudes, do que está previsto em lei, com a implantação de políticas eficazes, e ainda com a forma de conduta daqueles encarregados de cumprir essa mesma lei e de cuidar da recuperação dos menores infratores.

Não adianta o desenvolvimento de projetos pedagógicos, psicológicos, se tais medidas não são efetivamente implantadas, ou o são pela metade.

Também de nada resolverá se não se mudar a política de formação dos funcionários encarregados de trabalhar com a disciplina desses jovens.

Mas, parece que é mais fácil, e aparentemente, mais impactante, bem ao gosto da demagogia, reduzir a maioridade penal.

\section{REFERÊNCIAS}

BARROS, Monalisa Nascimento dos Santos; CONTINI, Maria de Lourdes Jeffery; KOLLER, Silvia Helena. Adolescência e Psicologia. Concepções, práticas e reflexões críticas. Brasília: Conselho Federal de Psicologia, 2002.

BORGES, Éverton André Luçardo. Adolescente infrator e políticas públicas para ressocialização. In: Âmbito Jurídico, Rio Grande, XVI, $n^{\circ}$ 117, out.2013. Disponível em: http://ambito-

juridico.com.br/site/?n_link=revista_artigos_leitura\&artigo_id=13694\&revisa_caderno=12.

Acesso em 04.ago.2015.

BRASIL. Decreto 5083, de 01/12/1926. Disponível em: http://www4.planalto.gov.br/legislacao/legislacao-1/decretos1/decretos1/anteriores-a1959\#content Acesso em 04.ago.2015.

Decreto $n .^{\circ}$ 17943-A, de 12/10/1927. Disponível em:

http://www4.planalto.gov.br/legislacao/legislacao-1/decretos1/decretos1/anteriores-a1959\#content. Acesso em 05.ago.2015.

- Lei $n .^{\circ} 5258$, de 02/06/1965. Disponível em:

http://www4.planalto.gov.br/legislacao/legislacao-1/leis-ordinarias/legislacao/legislacao- 
1/leis-ordinarias/1980-a-1960\#content. Acesso em 12.ago.2015.

- Lei n. ${ }^{\circ} 5439$, de 22/05/1968. Disponível em:

http://www4.planalto.gov.br/legislacao/legislacao-1/leis-ordinarias/legislacao/legislacao1/leis-ordinarias/1980-a-1960\#content. Acesso em 12.ago.2015.

. Lei $n .{ }^{\circ}$ 6697, de 10/12/1979. Disponível em:

http://www4.planalto.gov.br/legislacao/legislacao-1/leis-ordinarias/legislacao/legislacao1/leis-ordinarias/1980-a-1960\#content. Acesso em 04.08.2015.

. Lei . $^{\circ}$ 8069, de 13/07/1990. Disponível em:

http://www4.planalto.gov.br/legislacao/legislacao-1/leis-ordinarias/legislacao-1/leisordinarias/1990\#content. Acesso em 13.08.2015.

FELDMAN, Ruth Duskin; PAPALIA, Diane E. Desenvolvimento Humano. Tradução de Cristina Monteiro e Mauro de Campos Silva. Porto Alegre: AMGH Editora, 2013.

FOUCAULT, Michel. Vigiar e Punir. História da violência nas prisões. Tradução de Raquel Ramalhete. São Paulo: Petrópolis, 1987.

PRATTA, Elisângela Maria Machado Pratta; SANTOS, Manoel Antonio dos. Família e Adolescência: A Influência do contexto familiar no desenvolvimento psicológico de seus membros. In: Psicologia em Estudo. Maringá, v. 12, n. 2, p. 247-256, maio/ago.2007. 